THURSDAY, 15 JUNE 2017

Vasculitis clinical and pathogenic highlights

\section{OP0130 MEPOLIZUMAB FOR THE TREATMENT OF PATIENTS WITH EOSINOPHILIC GRANULOMATOSIS WITH POLYANGIITIS: A PHASE III RANDOMISED, PLACEBO-CONTROLLED TRIAL}

M.E. Wechsler ${ }^{1}$, P. Akuthota ${ }^{2}$, D. Jayne ${ }^{3}$, P. Khoury ${ }^{4}$, A. Klion ${ }^{4}$, C. Langford ${ }^{5}$, P.A. Merkel ${ }^{6}$, F. Moosig ${ }^{7}$, U. Specks ${ }^{8}$, M.C. Cid ${ }^{9}$, R. Luqmani ${ }^{10}$, J. Brown ${ }^{11}$, S. Mallett ${ }^{11}$, R. Philipson ${ }^{12}$, S.W. Yancey ${ }^{13}$, J. Steinfeld ${ }^{13}$, P.F. Weller ${ }^{14}$,

G. Gleich ${ }^{15}$. ${ }^{1}$ National Jewish Health, Denver; ${ }^{2}$ UC San Diego Health, la Jolla, United States; ${ }^{3}$ University of Cambridge, Cambridge, United Kingdom; ${ }^{4}$ NIAID, Bethesda; ${ }^{5}$ Cleveland Clinic, Cleveland; ${ }^{6}$ University of Pennsylvania, Philadelphia, United States; ${ }^{7}$ Schleswig-Holstein Mitte, Neumünster, Germany; ${ }^{8}$ Mayo Clinic, Rochester, United States; ${ }^{9}$ Hospital Clinic University of Barcelona, Barcelona, Spain; ${ }^{10}$ University of Oxford, Oxford; ${ }^{11}$ GSK, Uxbridge; ${ }^{12}$ Trizell Ltd, Oxford, United Kingdom; ${ }^{13}$ GSK, Research Triangle Park; ${ }^{14}$ Beth Israel Deaconess Medical Center, Boston; ${ }^{15}$ University of Utah Hospital, Salt Lake City, United States

Background: Mepolizumab reduces blood eosinophils with concomitant clinical improvement in some hypereosinophilic syndromes and eosinophilic asthma.

Objectives: To investigate the efficacy and safety of mepolizumab in patients with eosinophilic granulomatosis with polyangiitis (EGPA, Churg-Strauss).

Methods: We conducted a Phase III, randomised, placebo-controlled, doubleblind, parallel group, multi-centre study (NCT02020889) in patients with EGPA and a history of relapsing or refractory disease on stable therapy with prednisolone/prednisone $\geq 7.5-\leq 50 \mathrm{mg} /$ day with or without additional immunosuppressive therapy for $>4$ weeks. Patients were randomised 1:1 to receive mepolizumab $300 \mathrm{mg}$ or placebo subcutaneously, in addition to standard of care, every 4 weeks for 52 weeks. After Week 4, glucocorticoid dose could be tapered, per physician judgment, according to a suggested standard of care protocol. Co-primary endpoints (intent-to-treat [ITT] analysis) were accrued duration of remission (Birmingham Vasculitis Activity Score [BVAS]=0, prednisolone/prednisone dose $\leq 4 \mathrm{mg} /$ day) over 52 weeks; and the proportion of patients in remission at both Weeks 36 and 48. Secondary endpoints included average glucocorticoid dose during Weeks 49-52 and time to first EGPA relapse. Safety was also assessed.

Results: The ITT population included 136 randomised patients (mepolizumab $n=68$, placebo $n=68$ ). Baseline characteristics were similar between groups. Duration of remission accrued over 52 weeks was significantly prolonged with mepolizumab vs placebo (odds ratio: 5.91 [95\% confidence interval [Cl]: $2.68,13.03$ ] $; \quad<0.001)$; a significantly higher proportion of patients were in remission at Weeks 36 and 48 (32\% vs 3\%, odds ratio: 16.74 [95\% Cl: $3.61,77.56$ ]; $p<0.001)$. Significant reductions in average daily prednisolone/prednisone dose during Weeks 49-52 were seen with mepolizumab vs placebo (odds ratio: $0.20[95 \% \mathrm{Cl}: 0.09,0.41] ; \mathrm{p}<0.001$ ). Median (range) prednisolone/prednisone dose during Weeks $49-52$ was $5.0(0.0-113.4) \mathrm{mg} /$ day in the mepolizumab group and $10.0(0.0-46.3) \mathrm{mg} /$ day in the placebo group. Time to first EGPA relapse was significantly longer with mepolizumab vs placebo (hazard ratio: $0.32[95 \%$ $\mathrm{Cl}: 0.21,0.50] ; p<0.001)$. Rates of adverse events $(\mathrm{AEs})$ and serious AEs were similar for mepolizumab and placebo.

Conclusions: Treatment with mepolizumab significantly increased the likelihood and duration of remission, while reducing glucocorticoid use, in patients with EGPA, with a safety profile consistent with previous studies in severe asthma and EGPA. This demonstrates consistent and meaningful clinical benefits of mepolizumab in patients with EGPA.

Acknowledgements: Funding: GSK [115921] in collaboration with NIAID [U01 Al097073] and the Division of Intramural Research, NIAID, NIH). Abstract submitted to ATS 2017.

Disclosure of Interest: M. Wechsler Consultant for: Teva, AstraZeneca, BSCl, GSK, Novartis, sanofi, Vectura, Sunovion, Regeneron, Ambit bioscience, Meda, Mylan, Gliacure, Tunitas, Genentech, Theravance, Neurotronic, Sentien, P. Akuthota Grant/research support from: National Institutes of Health, Consultant for: Ambrx, Employee of: University of California San Diego, D. Jayne Grant/research support from: GSK, Consultant for: GSK, P. Khoury: None declared, A. Klion: None declared, C. Langford Grant/research support from: GlaxoSmithKline, BristolMyers Squibb, Genentech, P. Merkel: None declared, F. Moosig Grant/research support from: Roche, Consultant for: Roche, Chuagi, Lilly, GSK, U. Specks: None declared, M. Cid Consultant for: GSK, Novartis, Roche, Boehringer-Inhelheim, R. Luqmani Grant/research support from: Roche, GSK, Consultant for: Roche, GSK, J. Brown Shareholder of: GSK, Employee of: GSK, S. Mallett Shareholder of: GSK, Employee of: GSK, R. Philipson Employee of: Trizell Ltd, S. Yancey Shareholder of: GSK, Employee of: GSK, J. Steinfeld Shareholder of: GSK, Employee of: GSK, P. Weller: None declared, G. Gleich Shareholder of: Mutual funds, Grant/research support from: NIH, Consultant for: Genentech, Employee of: VAH, U Utah

DOI: 10.1136/annrheumdis-2017-eular.5610

\section{OP0131 OPTIMAL DOSE OF TOCILIZUMAB FOR THE TREATMENT OF GIANT CELL ARTERITIS: EFFICACY, SAFETY, AND} EXPOSURE-EFFICACY ANALYSIS FROM GIACTA

J.H. Stone ${ }^{1}$, K. Tuckwell ${ }^{2}$, S. Dimonaco ${ }^{2}$, M. Klearman ${ }^{3}$, N.L. Mallalieu ${ }^{4}$, M. Aringer ${ }^{5}$, D. Blockmans ${ }^{6}$, E. Brouwer ${ }^{7}$, M.C. Cid ${ }^{8}$, B. Dasgupta ${ }^{9}$, J. Rech ${ }^{10}$ C. Salvarani ${ }^{11}$, G. Schett ${ }^{12}$, H. Schulze-Koops ${ }^{13}$, R. Spiera ${ }^{14}$, S.H. Unizony ${ }^{1}$, N. Collinson ${ }^{2}$ on behalf of GiACTA Investigators. ${ }^{1}$ Harvard Med Sch, Boston, United States; ${ }^{2}$ Roche Products Ltd, Welwyn Garden City, United Kingdom;

${ }^{3}$ Genentech, S San Francisco; ${ }^{4}$ Roche Innovation Ctr, New York, United States; ${ }^{5}$ Abteilung für Rheumatologie, Dresden, Germany; ${ }^{6} U$ Hosp Gasthuisberg, Leuven, Belgium; ${ }^{7} U$ Groningen Med Ctr, Groningen, Netherlands; ${ }^{8}$ Hosp Clínic, $\cup$ Barcelona, IDIBAPS, Barcelona, Spain; ${ }^{9}$ Southend U Hosp, Westcliff-on-Sea, United Kingdom; ${ }^{10}$ Friedrich-Alexander-U Erlangen-Nürnberg, Erlangen,

Germany; ${ }^{11}$ Arcispedale Santa Maria Nuova-IRCCS, Reggio Emilia, Italy; ${ }^{12}$ Inst Clin Immunol, Erlangen; ${ }^{13}$ Div Rheum Clin Immunol, U Munich, Munich, Germany; ${ }^{14}$ Hosp Special Surg/Cornell, New York, United States

Background: GiACTA, a randomized, double-blind, placebo-controlled trial, evaluated the efficacy and safety of tocilizumab (TCZ), an IL-6 receptor- $\alpha$ inhibitor, in patients with giant cell arteritis (GCA). ${ }^{1,2}$

Objectives: Secondary analyses to evaluate the differential efficacy and safety of TCZ between patients with new-onset and relapsing GCA and to evaluate the TCZ exposure-efficacy relationship at week 52 of the trial.

Methods: Patients aged $>50$ years with active GCA were randomly assigned 1:1:2:1 to short-course prednisone $(\mathrm{PBO}+26)$, long-course prednisone (PBO+52) (26-week or 52-week prednisone taper + weekly subcutaneous [SC] placebo, respectively), weekly (TCZ-QW) or every-other-week (TCZ-Q2W) SC TCZ $162 \mathrm{mg}$ +26 -week prednisone taper. Subgroup analysis was performed by disease-onset status (new-onset vs relapsing) to evaluate the proportions of patients in sustained remission at week 52 and time to flare. The impact of TCZ exposure, categorized into high, medium and low tertiles, on time to flare was evaluated across all patients in all treatment arms.

Results: Randomization included 251 patients, 119 (47\%) with new-onset and 132 $(53 \%)$ with relapsing GCA, distributed evenly across groups. Higher proportions of patients achieved sustained remission in the TCZ vs placebo groups regardless of disease onset (new-onset, relapsing-TCZ-QW: 59.6\%, 52.8\%; TCZ-Q2W: $57.7 \%$, 47.8\%; PBO+26: 21.7\%, 7.4\%; PBO+52: $21.7 \%, 14.3 \%$, respectively). Patients with relapsing disease at baseline were in relapse-free remission longer and thus had lower risk for flare (hazard ratio) when treated with TCZ-QW than TCZ-Q2W. Hazard ratio $(99 \% \mathrm{Cl})$ for flare vs PBO+26 was $0.23(0.09-0.61)$ for TCZ-QW and $0.42(0.14-1.28)$ for TCZ-Q2W; vs PBO+52 it was $0.36(0.13-1.00)$ for TCZ-QW and $0.67(0.21-2.10)$ for TCZ-Q2W. TCZ exposure-efficacy analysis showed that most patients in the low exposure tertile had been treated with TCZ-Q2W (80\%) whereas those with medium and high exposure primarily received TCZ-QW $(84 \%$ and $98 \%$, respectively). Kaplan-Meier analysis demonstrated that patients with higher exposure benefited from a longer time to flare (Figure). Adverse events (AEs) were similar across groups. Serious AEs were reported in $15.0 \% \mathrm{TCZ}-\mathrm{QW}$, $14.3 \% \mathrm{TCZ}-\mathrm{Q} 2 \mathrm{~W}, 22.0 \% \mathrm{PBO}+26$ and $25.5 \% \mathrm{PBO}+52$ patients; rates were similar between new-onset and relapsing patients.

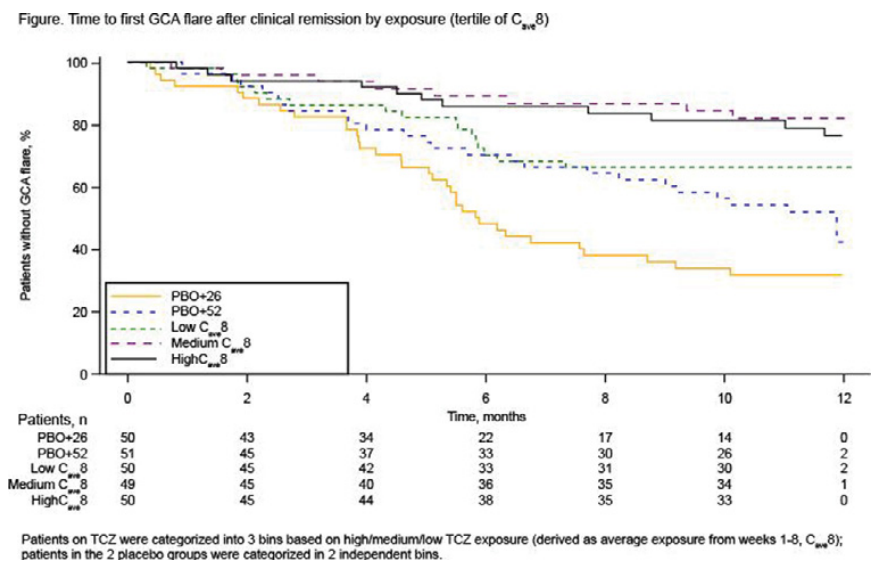

Conclusions: The compelling treatment effect of TCZ in GCA patients as measured by sustained remission to 52 weeks was consistent regardless of disease-onset status. Duration of relapse-free remission until flare was longer in patients with higher TCZ exposure, most notably in relapsing patients treated with TCZ-QW.

References:

[1] Unizony SH et al. Int J Rheumatol. 2013;2013:912562.

[2] Stone JH et al. 2016 ACR/ARHP Annual Mtg; Washington, DC; A911.

Disclosure of Interest: J. Stone Grant/research support from: Roche, Genentech, Xencor, Consultant for: Roche, Genentech, Xencor, K. Tuckwell Shareholder of: Roche, Employee of: Roche, S. Dimonaco Employee of: Roche Products Ltd., M. Klearman Employee of: Genentech, N. Mallalieu Shareholder of: Roche, Employee of: Roche, M. Aringer Speakers bureau: Roche, Chugai, D. Blockmans: 